\title{
Schedule Control, Work Interference With Family, and Emotional Exhaustion: A Reciprocal Moderated Mediation Model
}

\author{
Kun Yu \\ School of Labor and Human Resources, Renmin University of China, Beijing, China
}

\begin{abstract}
$T$ he current research drew upon the resource perspective (Grzywacz \& Marks, 2000; ten Brummelhuis \& Bakker, 2012) and firstly focused on the reciprocal mediation relationship between schedule control, work interference with family (WIF) and emotional exhaustion. First, the present study proposed that WIF mediates the negative relationship between schedule control and emotional exhaustion, and emotional exhaustion also mediates the negative relationship between schedule control and WIF. Second, family time adequacy was expected to play an amplifying role in the first path of the two mediations. Using a sample of 563 employees and adopting hierarchical linear modelling, the three-wave study first revealed that the emotional exhaustion mediates the relationship between schedule control and WIF while WIF also mediates the schedule control-emotional exhaustion relationship, which demonstrated a reciprocal mediation. Furthermore, the relationship between schedule control and emotional exhaustion, as well as the indirect effects of schedule control on WIF via emotional exhaustion, were stronger for employees with higher family time adequacy. Implications of the findings and future directions are discussed.
\end{abstract}

Keywords: schedule control, work interference with family, emotional exhaustion, family time adequacy

As the two most important realms of adult life (Andrews \& Withey, 1976), work and family are sometimes incompatible with each other, which causes work-family conflict (Frone, 2003; Greenhaus \& Beutell, 1985). Defined as 'a form of inter-role conflict in which the role pressures from the work and family domains are mutually incompatible in some respect' (Greenhaus \& Beutell, 1985, p. 77), work-family conflict, including work interference with family (WIF) and family interference with work (FIW), was considered a destructive construct that brings numerous adverse outcomes to individuals' work and life (Bedeian, Burke, \& Moffett, 1988; Burke, 1988; Frone, Russell, \& Cooper, 1992), such as low wellbeing (Diener \& Ryan, 2008), job dissatisfaction (Bacharach, Bamberger, \& Conley, 1991; Bedeian et al., 1988), depression (Frone et al., 1992), absenteeism (Goff, Mount, \& Jamison, 2006), turnover intention (Nohe \& Sonntag, 2014), and emotional exhaustion (Pleck, Staines, \& Lang, 1980).

For the deleterious consequences that work-family conflict leads to, organisations have adopted multiple policies, such as flexible work schedules, to give employees more control over their work time and reduce employees' WIF (Glass \& Fujimoto, 1995; Thomas \& Ganster, 1995). However, compared to the more prevalent research on the impact of other types of job control, such as decisionmaking authority and skill discretion (Karasek, 1979; Van der Doef \& Maes, 1999), schedule control, which refers to the flexibility of how much time is spent at work and where the work takes place (Thomas \& Ganster, 1995), has rarely been investigated (Kelly \& Moen, 2007) within organisations. To date, schedule control is noticeably disconnected from several important workplace outcomes, such as employees' emotional exhaustion, in the literature.

Moreover, beyond the work domain, although a few cross-sectional studies provide preliminary evidences about the negative association between schedule control and work-family conflict (Beutell, 2010; Hughes \& Parkes, 2007; Lapierre \& Allen, 2012), how employees' control over work schedules affects WIF, and how this impact relates to employees' emotional exhaustion, is far from clear. This is both a theoretical and practical void because, other than job control on 'how' to do the work, the control on 
'when' and 'where' to do the work also matters for both individuals and organisations.

In the present study, which drew upon a resources perspective (Grzywacz \& Marks, 2000; ten Brummelhuis \& Bakker, 2012) and was based on the job demandsresources model (Bakker \& Demerouti, 2007), a reciprocal mediation model is expected regarding the relationship among schedule control, WIF, and emotional exhaustion. First, it is proposed that schedule control has an indirect effect on their emotional exhaustion via WIF. Moreover, it is also proposed that schedule control has an indirect effect on their WIF via emotional exhaustion. In addition, when employees have a high level of family time adequacy, which refers to the time available for family (Van Horn, Bellis, \& Snyder, 2001), it is expected that a high level of schedule control would be more genuine for employees, and the negative effect of schedule control on emotional exhaustion and WIF would both be strengthened. The proposed model can be seen in Figure 1.

The investigation of the relationship between schedule control and WIF will contribute to the demands-resources model (Bakker \& Demerouti, 2007), the literature of workfamily conflict and emotional exhaustion, and the practice of flexible work schedule policy in three ways. First, through the hypothesised reciprocal mediation model, the present study will not only explain the possible reciprocal relationship between WIF and emotional exhaustion but also give a clearer picture of the reciprocal mediation relationship between schedule control, WIF, and emotional exhaustion. Second, the incorporation of family time adequacy will not only enrich the above picture by uncovering a necessary condition outside of the workplace but also expand the scope of the demands-resources model (Bakker \& Demerouti, 2007) out of the work domain. Third, findings of the current research will give organisations a clear message about the importance of work time control for employees, and a possible hint that employees' control of family time also matters at work.

\section{Theory Background and Hypothesis}

Schedule Control, Work Interference With Family, and Emotional Exhaustion

Compared to actual work schedule, schedule control depicts employees' perceived control over their work schedules (Fenwick \& Tausig, 2001). Drawing upon a resource perspective (Grzywacz \& Marks, 2000; ten Brummelhuis \& Bakker, 2012) and job demands-resources model (Bakker \& Demerouti, 2007), I argue that there is a reciprocal mediation between schedule control, WIF, and emotional exhaustion. Specifically, schedule control not only has a negative impact on employees' WIF through their emotional exhaustion, but also negatively influences employees' emotional exhaustion via their WIF.

The core idea of the job demands-resources model is that individuals experience psychological and physical strain if job demands are high or resources are insufficient
(Bakker \& Demerouti, 2007). Work schedule can be seen as a job demand that is imposed by the organisation (Beutell, 2010). On the contrary, schedule control, which focuses on when and where to do the job (Fenwick \& Tausig, 2001), can be seen as providing autonomy and a job resource that allows employees to allocate their time and energy more freely and efficiently. Thus, it is reasonable to argue that if employees have a high level of schedule control, they may experience fewer job demands and more job resources, and, thus, have a lower level of job strain. As a result, employees' emotional exhaustion, as a type of psychological strain (Maslach \& Jackson, 1981), would be reduced. Therefore, it is predicted that:

Hypothesis 1. Schedule control is negatively associated with emotional exhaustion.

Moreover, based on the work-home resources model (ten Brummelhuis \& Bakker, 2012), on the one hand, a lack of resources in one domain may lead to depletion of resources in another domain (i.e., loss spiral). On the other hand, sufficient resources in one domain could produce resources for another domain (i.e., gain spiral). Thus, abundant resources in the workplace would not only reduce depletion of family resources but also spill over to family domain and help individuals to deal better with their family life (Grzywacz \& Marks, 2000; ten Brummelhuis \& Bakker, 2012). Thus, a high level of schedule control on work would help to reduce work interference with family. Therefore, it is predicted that:

Hypothesis 2. Schedule control is negatively associated with work interference with family.

The resource perspective posits that individuals have a finite amount of resources to use in all aspects of work and life, and ineffective allocation of resources will lead to psychological strain (Grzywacz \& Marks, 2000). Based on the demands-resources model (Bakker \& Demerouti, 2007), emotional exhaustion can be seen as a consequence of high demands and few resources. Since work interference with family is an indicator of personal resources (e.g., time) insufficiency (Greenhaus \& Beutell, 1985), it is reasonable to expect that under a high level of work interference with family, individuals' emotional exhaustion would also be high. Moreover, emotional exhaustion could also be the antecedent of resource depletion. This is because, in order to cope with emotional exhaustion, employees have to consume their limited resources (Schaufeli \& Bakker, 2004). This can lead to a vicious cycle and leave insufficient resources available for family, which can trigger WIF. Combining the above reasoning, it is likely that WIF and emotional exhaustion have a reciprocal relationship. Thus, it is predicted that:

Hypothesis 3. WIF and emotional exhaustion have a positive and reciprocal relationship over time.

To sum up, schedule control can act as a form of job resources that helps employees to better manage their personal resources for family and leads to a low level of WIF. The low level of WIF should cause less strain and 


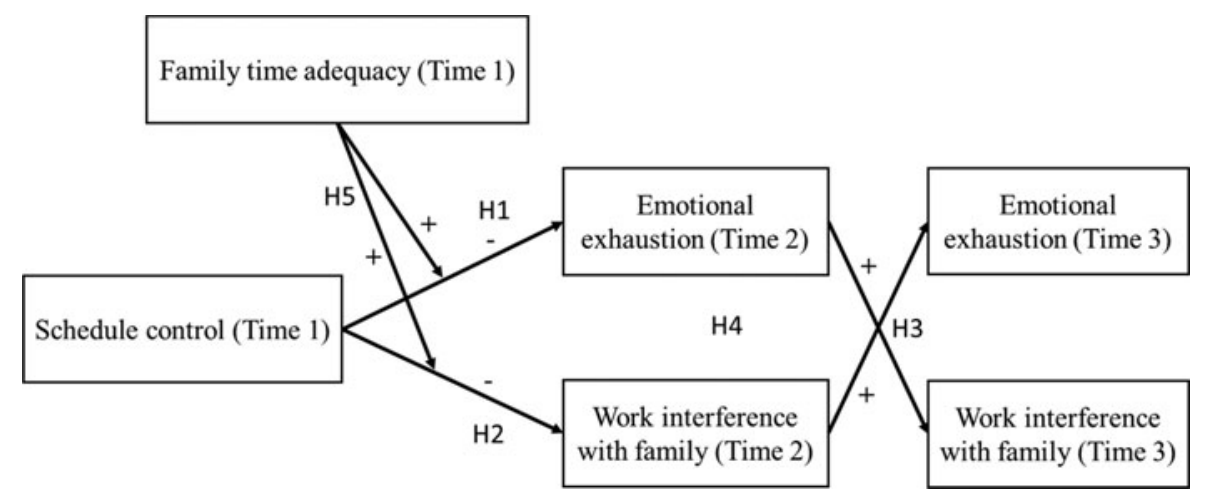

Figure 1

Reciprocal mediation between schedule control, work interference with family and emotional exhaustion, and the moderating role of family time adequacy.

therefore a lower level of emotional exhaustion. Simultaneously, schedule control can also help individuals to gain control and have less job strain, which should lead to a lower level of emotional exhaustion. With a lower level of emotional exhaustion, individuals would use fewer resources to deal with their exhaustion, which would benefit the family and reduce WIF. Thus, it is predicted that:

Hypothesis 4. WIF mediates the relationship between schedule control and emotional exhaustion, while emotional exhaustion mediates the relationship between schedule control and work interference with family.

\section{The Moderating Role of Family Time Adequacy}

Based on the resources allocation theory (Grzywacz \& Marks, 2000) and conservation of resource theory (Hobfoll, 1989), ten Brummelhuis and Bakker (2012) developed a resource perspective on the work-family relationship, namely the work-home resources model, and explained how personal resources flow between work and family domains. Combining the work-home resources model and job demands-resources model, it is reasonable to argue that family demands or resources, such as family time adequacy, may also play a role in the relationship between schedule control, emotional exhaustion, and WIF.

Family time adequacy refers to individuals' perception of time resources available for family (Van Horn et al., 2001). Acting as a form of family resources, family time adequacy and schedule control represent two parts of personal resources in the work and family domains respectively. Based on the work-home resources model (ten Brummelhuis \& Bakker, 2012), sufficient resources in one domain may not only reduce depletion of resources in another domain but also produce resources for another domain. Thus, employees with high family time adequacy not only have enough family time resources but may provide additional resources for work on the basis of the existing resources from schedule control.

Given that a high level of schedule control would reduce the depletion of family resources and decrease WIF, a high level of family time adequacy would strengthen the negative effect of schedule control on WIF from both work and family aspects. On the one hand, a high level of family time adequacy, as an abundant family resource, would help to enrich the whole family resources and make it less easy to be depleted. On the other hand, this family resource could also spill over to the work domain and enrich the whole work resources, which would reduce the depletion of resources in anther domain, such as family, and finally reduce work interference with family. In other words, I expect that a higher level of family time adequacy would amplify the negative association between schedule control and emotional exhaustion.

In contrast, employees who have a low level of family time adequacy do not have enough family time resources. Hence, based on the work-home resources model (ten Brummelhuis \& Bakker, 2012), they are more likely to deplete the limited resource, especially time resources at work, and cause the conflict between work and family. Thus, employees with a low level of family time adequacy would be less likely to have a low level of WIF when they have a higher level of schedule control than their colleagues with high family time adequacy. As proposed above, that WIF mediates the relationship between schedule control and emotional exhaustion, it is anticipated that family time adequacy, as a family resource, will moderate the indirect relationship between schedule control and WIF through emotional exhaustion. Therefore, it is predicted that:

Hypothesis 5a. Family time adequacy moderates the first stage of the indirect relationship between schedule control and emotional exhaustion via work interference with family. Specifically, the negative relationship between schedule control and work interference with family is stronger when family time adequacy is high.

Moreover, given that job resources are expected to be associated with a low level of job strain, such as emotional exhaustion, it is reasonable to argue that employees with high family time adequacy, which act as an abundant family resource, would be less likely to deplete their job resources. Thus, they would be more likely to have a low level of emotional exhaustion when they have a higher 
level of schedule control than their colleagues with low family time adequacy. In other words, it was expected that a higher level of family time adequacy would amplify the negative association between schedule control and emotional exhaustion.

In contrast, employees with low family time adequacy do not have enough time resources for the family. Therefore, they are more likely to deplete resources at work and thus perceive that fewer job resources are available than employees with high family time adequacy. Given the association between resources and strain, employees with low family time adequacy would be more likely to have a high level of emotional exhaustion regardless of the level of schedule control. As proposed above, that emotional exhaustion mediates the relationship between schedule control and WIF, it is anticipated that family time adequacy, as a family resource, will moderate the indirect relationship between schedule control and WIF through emotional exhaustion. Therefore, it is predicted that:

Hypothesis $5 \boldsymbol{b}$. Family time adequacy moderates the first stage of the indirect relationship between schedule control and work interference with family via emotional exhaustion. Specifically, the negative relationship between schedule control and emotional exhaustion is stronger when family time adequacy is high.

\section{Method}

\section{Participants and Procedure}

For this study, the data were collected as part of a large, publicly available dataset called the Work, Family, and Health Study (WFHS; Bray et al., 2013). The participants were employed in the 14 centres of an extended health care company. Employees who worked 22 or more hours per week in direct patient care on the day or evening shifts were eligible to participate in the present study. At baseline (Time 1), 799 employees reported their schedule control and family time adequacy. After 6 months, at Time 2, employees' emotional exhaustion and WIF were measured. Finally, 12 months after Time 1, employees' emotional exhaustion and WIF were measured at Time 3. Of the 799 participants, 563 (response rate $=70.46 \%$ ) completed the answer on the study variables of the current research across all three waves. The average age of the 563 subjects was $39.88(S D=12.19)$; $90.6 \%$ were female, $32.3 \%$ had a high school degree, and 13\% had a bachelor's degree or above.

\section{Measures}

Schedule control. The measure of schedule control was adopted from Thomas and Ganster's (1995) 14-item control scale. Eight items regarding control over work hours were used. Participants were asked to think about what they feel or believe is realistic for them and answered questions about their control over work hours using a 5point Likert scale (from $1=$ strongly disagree to $5=$ strongly agree). A sample item is 'How much choice do you have over when you take vacations or days off?' The Cronbach's alpha for the scale was .66.

Family time adequacy. Family time adequacy was measured with a seven-item scale adopted from the Family Resource Scale - Revised (FRS; Van Horn et al., 2001). The original FRS consists of 30 items that assesses a family member's perception of resources available for the family. Participants were asked to rate their agreement on a 5-point Likert scale (from $1=$ not at all adequate to $6=$ almost always adequate). A sample item is 'To what extent is there enough time to care for the needs of other family members (spouse, parents, in-laws)?' The Cronbach's alpha for the scale was .67.

Emotional exhaustion. Emotional exhaustion was measured by the three-item emotional exhaustion dimension of the Maslach Burnout Inventory (MBI; Maslach \& Jackson, 1986). Participants were asked to rate how their work makes them feel on a 7-point Likert scale (from $1=$ never to $7=$ every day). A sample item is 'You feel emotionally drained from your work. How often do you feel this way?' The Cronbach's alpha for the scale was .89 .

Work interference with family. Work interference with family was measured by Netemeyer and Boles' (1996) fiveitem, work-family conflict scale. Participants were asked to think about the past 6 months and rate their agreement on a 5-point Likert scale (from $1=$ strongly disagree to $5=$ strongly agree). A sample item is 'The demands of your work interfere with your family or personal time'. The Cronbach's alpha for time-based, strain-based and behaviour-based WIF was 90 .

Control variables. Participants' gender and age were controlled in the current study, as they are found to affect work-family conflict (Michel, Kotrba, Mitchelson, Clark, \& Baltes, 2011). Participants' sleep time was also controlled, as enough and high-quality sleep were considered to be an individual's important resource to deal with work tasks (Diestel, Rivkin, \& Schmidt, 2015). Sleep time was measured at Time 1 by participants' self-reports on how many hours they were sleeping per day on average.

\section{Results}

\section{Preliminary Analysis}

As all participants in the current study were working in 14 teams, it is possible that the nested data were nonindependent. Thus, intra-class coefficients (ICCs; Shrout \& Fleiss, 1979) of the study variables were computed. The ICC1s, which indicate the variance explained by group membership, were .05 for schedule control, .00 for family time adequacy, .03 for Time 2 emotional exhaustion, .03 for Time 2 WIF, .01 for Time 3 emotional exhaustion, and .01 for Time 3 WIF. The ICC2s, which indicate the reliability of group means, were .68 for Time 1 schedule control, .13 for Time 1 family time adequacy, .54 for Time 2 emotional exhaustion, .53 for Time 2 WIF, .17 for Time 3 emotional exhaustion, and .24 for WIF Time 3. According to Kenny (1995), the ICC1s of .01 is considered 
a small group effect, .10 is considered a medium group effect, and .15 a large group effect. Since the ICC1s of study variables in the current research ranged from .00 to .05 when treating the team as group variable, there was considerable groupness regarding the current research model. To eliminate the group effect, hierarchical linear modelling (HLM) using Mplus 7 (Muthén \& Muthén, 1998-2012) was adopted, and the group-level variances of all study variables were controlled in the further analysis.

\section{Tests of Discriminant Validity}

To examine whether key constructs and covariates in the current study (i.e., schedule control, family time adequacy at Time 1, emotional exhaustion and WIF at Time 2, and emotional exhaustion and WIF at Time 3) were distinguishable from each other, a confirmatory factor analysis (CFA) using Mplus 7 (Muthén \& Muthén, 1998-2012) was conducted. CFA results indicated that the six-factor measurement model (i.e., all variables are independent of each other) fitted the data well, $\chi^{2}(419)=1063.59$, $p<.01$, Comparative Fit Index $(\mathrm{CFI})=.92$, Tucker-Lewis Index $(\mathrm{TLI})=.91$, Root Mean Square Error of Approximation $($ RMSEA) $=.05$. The six-factor model fitted the data better than the three-factor model (in which variables in the same wave were combined), $\chi^{2}(431)=3146.87, p<$ $.01, \mathrm{CFI}=.65$, TLI $=.62$, RMSEA $=.11$, and one-factor model (in which all variables were combined), $\chi^{2}(434)=$ $4098.65, p<.01, \mathrm{CFI}=.53, \mathrm{TLI}=.49, \mathrm{RMSEA}=.12$. These results provided support for the discriminant validity of the constructs in the present study.

The means, standard deviations, correlations and reliabilities among the study variables are presented in Table 1. Schedule control was negatively associated with both emotional exhaustion and WIF at Time 2 (for emotional exhaustion, $r=-.13, p<.01$; for WIF, $r=-.17, p<.01$ ) and Time 3 (for emotional exhaustion, $r=-.15, p<.01$; for WIF, $r=-.17, p<.01)$. Family time adequacy was also negatively associated with both emotional exhaustion and WIF at Time 2 (for emotional exhaustion, $r=-.16, p<$ .01 ; for WIF, $r=-.28, p<.01$ ) and Time 3 (for emotional exhaustion, $r=-.22$, $p<.01$; for WIF, $r=-.30, p<$ $.01)$. Moreover, schedule control was positively associated with family time adequacy $(r=.22, p<.01)$. Furthermore, emotional exhaustion at Time 2 was positively associated with WIF at Time $3(r=.36, p<.01)$, while WIF at Time 2 was also positively associated with emotional exhaustion at Time $3(r=.37, p<.01)$. With respect to control variables, gender was negatively correlated with emotional exhaustion at both Time $2(r=-.13, p<.01)$ and Time $3(r=-.18, p<.01)$, and WIF at both Time $2(r=-.15$, $p<.01)$ and Time $3(r=-.11, p<.01)$. Sleep time was positive related with schedule control at Time $1(r=.08, p$ $<.05)$ and negatively correlated with emotional exhaustion at Time $2(r=-.09, p<.05)$. Thus, gender, age, and sleep time were controlled in the further analysis.

\section{Hypothesis Tests}

To examine the role of family time adequacy in the relationship between schedule control and WIF via emotional exhaustion and in the relationship between schedule control and emotional exhaustion via WIF, the 'first stage moderation model' approach (Edwards \& Lambert, 2007), in which the moderating effect takes place on the first stage of the indirect effect of an independent variable on a dependent variable through a mediator, was used in the current study. In the present research model, emotional exhaustion plays a mediating role in the relationship between schedule control and WIF, while WIF also plays a mediating role in the relationship between schedule control and emotional exhaustion. Family time adequacy moderated the path from both schedule control to emotional exhaustion and the path from schedule control to WIF. Thus, there were two conditional indirect effects of schedule control on both WIF and emotional exhaustion at different levels of family time adequacy. In addition, the path analysis of structural equation modelling (SEM) and HLM approach of Mplus 7 (Muthén \& Muthén, 1998-2012) were used to estimate the proposed research model, while including the group level variances into the analysis to rule out the possible group effect.

Hypothesis 1 and Hypothesis 2 proposed that schedule control negatively associated with both WIF and emotional exhaustion, after controlling for gender, age and sleep time, and the direct and negative effect of schedule control on Time 2 emotional exhaustion was significant (estimate $=-.27, S E=.11, p<.01,95 \%$ CI $[-.49,-.05]$ ). Similarly, the direct and negative effect of schedule control on Time 2 WIF was also significant (estimate $=-.19, S E$ $=.05, p<.01,95 \%$ CI $[-.28,-.11])$. Thus, Hypothesis 1 and Hypothesis 2 were both supported.

Hypothesis 3 proposed a cross-lagged reciprocal relationship and Hypothesis 4 proposed a reciprocal mediation. Reciprocal effect and reciprocal mediation were tested using the analytic procedure of reciprocal relationships from Griffin (1997) and Meier and Spector (2013). Four time-lagged paths are needed to calculate the possible reciprocal relationship between variable $\mathrm{X}$ and $\mathrm{Y}$ at two time points, including path Time $1 \mathrm{X}$ to Time $2 \mathrm{Y}$, path Time $1 \mathrm{X}$ to Time $2 \mathrm{X}$, path Time $1 \mathrm{Y}$ to Time 2 $\mathrm{X}$, and path Time $1 \mathrm{Y}$ to Time $2 \mathrm{Y}$. A reciprocal effect is demonstrated if the path from Time $1 \mathrm{X}$ to Time $2 \mathrm{Y}$, while controlling for Time $1 \mathrm{Y}$, and the path from Time 1 $\mathrm{Y}$ to Time $2 \mathrm{X}$, while controlling for Time $1 \mathrm{X}$, are both significant (Lian, Ferrin, Morrison, \& Brown, 2014; Meier \& Spector, 2013). Addressing the above strategy, a reciprocal mediation in the current study is considered valid if the path from the Time 1 schedule control to Time 3 emotional exhaustion via Time 2 WIF, while controlling for Time 2 emotional exhaustion, and the path from Time 1 schedule control to Time 3 WIF via Time 2 emotional exhaustion, while controlling for Time 2 WIF, are both significant. 


\begin{tabular}{|c|c|c|c|c|c|c|c|c|c|c|c|}
\hline Variable & $M$ & $S D$ & 1 & 2 & 3 & 4 & 5 & 6 & 7 & 8 & \\
\hline 1. Gender & 1.91 & 0.29 & - & & & & & & & & \\
\hline 2. Age & 39.88 & 12.19 & .05 & - & & & & & & & \\
\hline 3. Time 1 Sleep & 6.05 & 1.49 & .04 & .04 & - & & & & & & \\
\hline 4. Time 1 Schedule control & 2.62 & 0.74 & .01 & .01 & $.08^{*}$ & (.66) & & & & & \\
\hline 5. Time 1 FTA & 3.45 & 0.64 & $.14^{* *}$ & .07 & .07 & $.22^{* *}$ & $(.67)$ & & & & \\
\hline 6. Time $2 \mathrm{EE}$ & 4.28 & 1.69 & .01 & $-.13^{* *}$ & $-.09 *$ & $-.13^{* *}$ & $-.16^{* *}$ & $(.89)$ & & & \\
\hline 7. Time 2 WIF & 2.68 & 0.87 & .04 & $-.15^{* *}$ & -.07 & $-.17^{* *}$ & $-.28^{* *}$ & $.44^{* *}$ & (.89) & & \\
\hline 8. Time 3 EE & 4.19 & 1.67 & -.02 & $-.18^{* *}$ & -.08 & $-.15^{* *}$ & $-.22^{* *}$ & $.68^{* *}$ & $.37^{* *}$ & $(.89)$ & \\
\hline 9. Time 3 WIF & 3.36 & 0.87 & .01 & $-.11^{* *}$ & -.03 & $-.17^{* *}$ & $-.30^{* *}$ & $.36 * *$ & $.65^{* *}$ & $.44^{* *}$ & $(.90)$ \\
\hline
\end{tabular}

Note: $N=563$. Reliability coefficients are reported along the diagonal. FTA = family time adequacy; EE = emotional exhaustion; WIF = work interference with family. Gender was coded as follows: 1 = male, 2 = female; Educational level was coded as follows: 1 = Grade 1 through 8, 2 = Grade 9 through 11 (some high school), $3=$ Grade 12 or high school graduate, 4 = college $1-3$ years (some college or technical school), $5=$ college 4 years or more (college graduate). ${ }^{*} p<.05 ;{ }^{* *} p<.01$.

First, after incorporating gender, age, and sleep time as controls, the direct effect from Time 2 WIF to Time 3 emotional exhaustion, while controlling for Time 2 emotional exhaustion (estimate $=.13, S E=.05, p<.01,95 \%$ CI $[.04, .23])$, and the direct effect from Time 2 emotional exhaustion to Time 3 WIF, while controlling for Time 2 WIF (estimate $=.05, S E=.02, p<.05,95 \%$ CI $[.00, .09]$ ), were both significant, which indicated a cross-lagged reciprocal effect. Thus, Hypothesis 3 was supported.

Next, after incorporating gender, age, and sleep time as controls, the direct effect from Time 1 schedule control to Time 3 emotional exhaustion (estimate $=-.15, S E$ $=.05, p<.01,95 \% \mathrm{CI}[-.25,-.04])$ and Time $3 \mathrm{WIF}$ (estimate $=-.08, S E=.04, p<.05,95 \%$ CI $[-.15, .00])$ were both significant. After incorporating Time 2 WIF and Time 2 emotional exhaustion as mediators and controls respectively, the direct effect from Time 1 schedule control to Time 3 emotional exhaustion was still significant but weaker (estimate $=-.12, S E=.06, p<.05,95 \% \mathrm{CI}[-.23$, $-.01])$, and the direct effect from Time 1 schedule control to Time 3 WIF was not significant (estimate $=-.07, S E$ $=.04, n s, 95 \%$ CI $[-.14, .01])$. The indirect effect from Time 1 schedule control to Time 3 emotional exhaustion via Time 2 WIF, while controlling for Time 2 emotional exhaustion (estimate $=-.03, S E=.01, p<.05,95 \% \mathrm{CI}$ $[-.05, .00])$, and the indirect effect from Time 1 schedule control to Time 3 WIF via Time 2 emotional exhaustion, while controlling for Time 2 WIF (estimate $=-.01, S E=$ $.01, p=.05,95 \%$ CI $[-.03, .00])$, were both significant. The proportion of mediation effect was $20 \%$ for the path from schedule control to Time 3 emotional exhaustion via Time 2 WIF, and was $15.67 \%$ for the path from schedule control to Time 3 WIF via Time 2 emotional exhaustion. Thus, Hypothesis 4 was supported.

Following the procedure suggested by Preacher et al. (2007), the proposed moderated mediation hypotheses (Hypothesis 4) was examined. As shown in Table 2, the results first revealed that the schedule control-family time adequacy interactive effect on Time 2 emotional exhaustion was significant (estimate $=-.37, S E=.11, p<.01$, $95 \%$ CI $[-.58,-.16])$, but not significant on Time 2 WIF (estimate $=-.07, S E=.08, n s, 95 \% \mathrm{CI}[-.23, .08]) . \mathrm{A}$ simple slopes test at \pm 1 standard deviation of family time adequacy was also performed, the results of which are presented in Figure 2. Schedule control was negatively related to emotional exhaustion for employees with high family time adequacy $(+1 S D$; estimate $=-.43, S E=.12, p<.01$, $95 \%$ CI $[-.67,-.18])$, but not significant for employees with low family time adequacy $(-1 S D$; estimate $=.04, S E$ $=.13, n s, 95 \%$ CI $[-.22, .30])$.

Moreover, a moderated mediation index (Hayes, 2013) showed that family time adequacy significantly moderated the indirect effect of schedule control on Time 3 WIF through Time 2 emotional exhaustion (estimate $=-.02$, $S E=.01, p=.05,95 \%$ CI $[-.03, .00])$. Specifically, the indirect effect was significant when family time adequacy was high $(+1 S D$, estimate $=-.02, S E=.01, p<.05$, $95 \%$ CI $[-.04,-.001])$, and was not significant when family time adequacy was low $(-1 S D$, estimate $=.00, S E$ $=.01, n s, 95 \%$ CI $[-.01, .02])$. However, the moderating effect of family time adequacy on the indirect effect from schedule control to Time 3 emotional exhaustion via Time 2 WIF was not significant (moderated mediation index $=-.01, S E=.01, n s, 95 \%$ CI $[-.02, .01])$. Thus, Hypothesis $5 \mathrm{~b}$ was supported, and Hypothesis $5 \mathrm{a}$ was not supported.

\section{Discussion}

Drawing upon the resources perspective (Grzywacz \& Marks, 2000; ten Brummelhuis \& Bakker, 2012) and job demands-resources model (Bakker \& Demerouti, 2007), the current research examined the relationship between schedule control, WIF and emotional exhaustion, and the moderating role of family time adequacy. Specifically, time-lagged data were collected to examine whether WIF mediates the relationship between schedule control and emotional exhaustion and whether emotional exhaustion mediates the relationship between schedule control and WIF; and further, whether family time adequacy moderates the indirect relationship between schedule control and WIF via emotional exhaustion, and the indirect relationship between schedule control and emotional exhaustion via WIF. 
Table 2

Regression Results Controlling for Gender, Age, Sleep, Time 2 Emotional Exhaustion and Time 2 WIF

\begin{tabular}{|c|c|c|c|c|c|c|c|c|}
\hline \multirow[t]{2}{*}{ Predictor } & \multicolumn{2}{|c|}{ Time $2 \mathrm{EE}$} & \multicolumn{2}{|c|}{ Time 2 WIF } & \multicolumn{2}{|c|}{ Time $3 \mathrm{EE}$} & \multicolumn{2}{|c|}{ Time 3 WIF } \\
\hline & Estimate & $S E$ & Estimate & SE & Estimate & SE & Estimate & $S E$ \\
\hline Gender & 0.23 & 0.16 & $0.26^{\dagger}$ & 0.15 & -0.06 & 0.13 & 0.02 & 0.09 \\
\hline Age & $-0.02 *$ & 0.01 & $-0.01^{* *}$ & 0.00 & $-0.01^{* *}$ & 0.01 & -0.00 & 0.00 \\
\hline Sleep & $-0.08^{\dagger}$ & 0.05 & -0.03 & 0.02 & -0.01 & 0.03 & 0.02 & 0.02 \\
\hline Time 1 Schedule control & $-0.19^{\dagger}$ & 0.10 & $-0.13^{* *}$ & 0.04 & -0.09 & 0.05 & -0.04 & 0.04 \\
\hline Time 1 Family time adequacy & $-0.37^{* *}$ & 0.13 & $-0.36^{* *}$ & 0.07 & $-0.24^{* *}$ & 0.08 & $-0.16^{* *}$ & 0.05 \\
\hline Time $1 \mathrm{SC} \times \mathrm{FTA}$ & $-0.37^{* *}$ & 0.11 & -0.07 & 0.08 & -0.03 & 0.08 & -0.01 & 0.06 \\
\hline Time $2 \mathrm{EE}$ & & & & & $0.62^{\text {** }}$ & 0.03 & $0.05^{\dagger}$ & 0.02 \\
\hline Time 2 WIF & & & & & 0.09 & 0.05 & $0.57^{* *}$ & 0.04 \\
\hline$R^{2}$ & $0.07^{* *}$ & & $0.12^{* *}$ & & $0.49^{* *}$ & & $0.45^{* *}$ & \\
\hline
\end{tabular}

Note: $N=563 . \mathrm{SC}=$ schedule control; FTA = family time adequacy; $\mathrm{EE}=$ emotional exhaustion; $\mathrm{WIF}=$ work interference with family; $S E=$ standard error. ${ }^{\dagger} p<.10, * p<.05,{ }^{* *} p<.01$

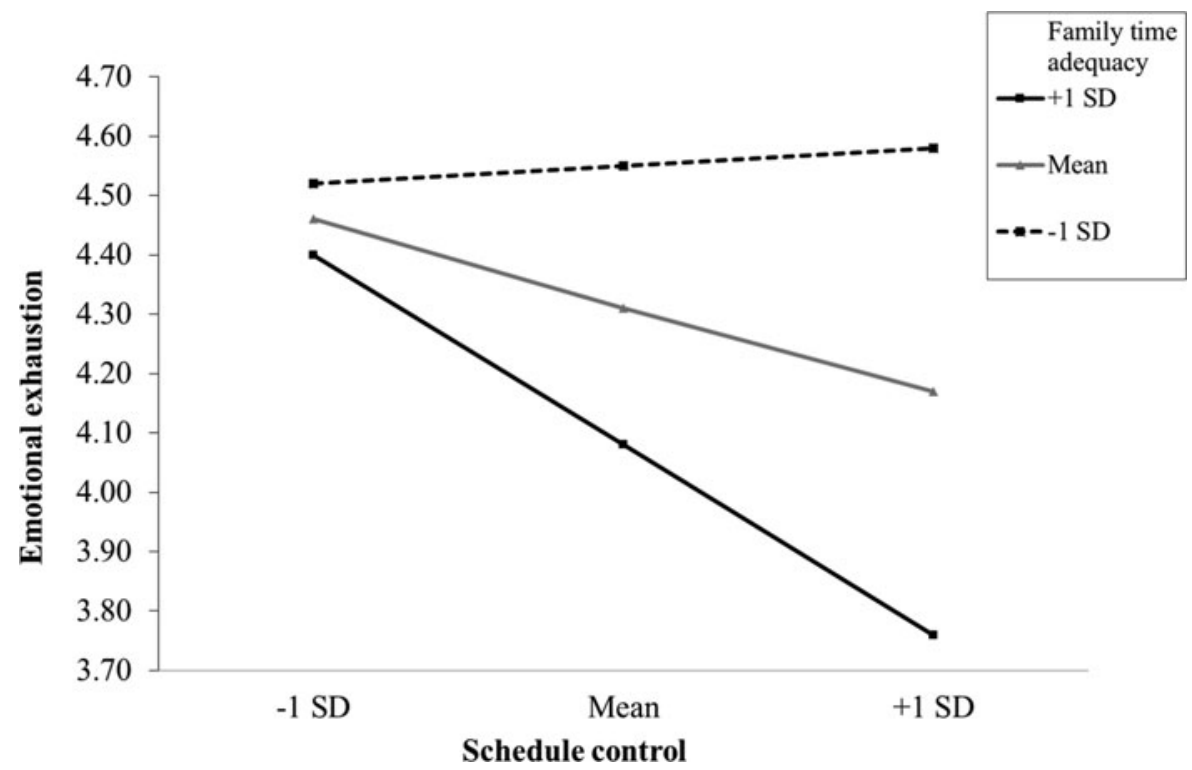

\section{Figure 2}

The interaction between schedule control and family time adequacy predicting emotional exhaustion. SD = standard deviation.

The findings of the current research first supported the research hypotheses of reciprocal mediation. Consistent with the resources perspective (Grzywacz \& Marks, 2000; ten Brummelhuis \& Bakker, 2012) and the job demandsresources model (Bakker \& Demerouti, 2007), research results first showed that WIF mediates the relationship between schedule control and emotional exhaustion. Moreover, emotional exhaustion also mediates the relationship between schedule control and work-family conflict. These results suggest that employees with a high level of control over their work schedule, as a job resource, would simultaneously have a low level of work-family conflict through the decrease of job strains such as emotional exhaustion, and have a low level of emotional exhaustion via the decrease of WIF.

Furthermore, the findings of the current research also provide support for the moderating role of family time adequacy in the relationship between schedule control, WIF and emotional exhaustion. First, family time adequacy had a significant moderating effect on the relationship between schedule control and WIF. Then a moderated mediation analysis revealed that the indirect effect of schedule control on emotional exhaustion via WIF was stronger for employees with a high level of family time adequacy. Second, family time adequacy had a significant moderating effect on the relationship between schedule control and emotional exhaustion. Then a moderated mediation analysis revealed that the indirect effect of schedule control on WIF via emotional exhaustion was stronger for employees with a high level of family time adequacy.

\section{Theoretical and Practical Implications}

The current research contributes to the existing literature on both the work-family relationship and the job demands-resources model in two ways. First, the present study found a reciprocal relationship between WIF and emotional exhaustion over time; and, based on this, revealed a reciprocal mediation between schedule control, 
WIF, and emotional exhaustion. Consistent with the workhome resources model (ten Brummelhuis \& Bakker, 2012), schedule control, as a job resource that could be spilled over to family, is not only associated with emotional exhaustion through the impact of WIF, but correlated to WIF via the effect of emotional exhaustion. The reciprocal path between emotional exhaustion and WIF uncovered a vicious circle of resource depletion between work and family, and the incorporation of schedule control could turn the vicious circle to a positive cycle.

Second, the current research extends the scope of demands-resources model domain (Bakker \& Demerouti, 2007), since the traditional demands-resources model is only within organisations. The current study incorporated family time adequacy as a boundary condition and found that the impact of schedule control on emotional exhaustion depends on the level of family time adequacy. This results suggest that the traditional demands-resources model needs to be more comprehensively constructed. Specifically, looking at the antecedents of organisational outcomes, the demands-resources model should simultaneously and naturally contain both demands and resources from work and family.

The current study also provides empirical support for the work-home resources model. While ten Brummelhuis and Bakker (2012) released eight propositions regarding the resources-based, work-family balance, they called for a validity test of the proposed model. As found in the current study, family time adequacy, a form of family resources, would strengthen the negative relationship between schedule control (i.e., a form of job resources) and emotional exhaustion. This result supports a unified view of personal resources across domains of work and family. Sufficient resources in one domain would trigger a gain spiral and produce more resources for another domain, while insufficient resources in one domain would bring a loss spiral and deplete resources of another domain.

The hypothesis of the moderating effect of family time adequacy in the relationship between schedule control and WIF was not supported. A possible explanation could be that compared to spilling over to the work domain and strengthening the effect of schedule control on emotional exhaustion, the effect of family time adequacy on WIF may be parallel with the effect of schedule control. As can be seen in Table 2, while the effect of family time adequacy on emotional exhaustion was significant (estimate $=-.37$, $p<.01)$, the effect of schedule control was not significant (estimate $=-.19, n s)$. Given the significant interaction (estimate $=-.37, p<.01$ ), these results indicated that the effect of schedule control was highly influenced by family time adequacy. However, although the effect of family time adequacy on WIF was significant (estimate $=-.36$, $p<.01$ ), the effect of schedule control on WIF was significant too (estimate $=-.13, p<.01$ ), indicating a parallel effect.

The findings of the current study offer several practical implications. First, considering the positive effect of work schedule control on reducing emotional exhaustion and work-family conflict, organisations should promote a flexible work schedule policy. Second, since reciprocal mediation exists between schedule control, emotional exhaustion and WIF, if organisations have difficulties making work schedules more flexible, in order to reduce employees' work-family conflict, they could try other possible ways, such as relaxation classes, to help employees to relieve their emotional exhaustion. Similarly, in order to reduce employees' emotional exhaustion, organisations could try to help employees to reduce their conflicts with time, strain, and behaviour between work and family (Greenhaus \& Beutell, 1985). Third, organisations should not only pay attention to employees' work schedules, but also to their perceived adequacy of family time. Since insufficient family time would weaken the effect of schedule control on emotional exhaustion, target treatment such as time management training is needed for employees with low family time adequacy.

\section{Limitations And Future Directions}

There were also some limitations in the current research. First, drawing upon a resources perspective (Grzywacz \& Marks, 2000; ten Brummelhuis \& Bakker, 2012), it was argued that emotional exhaustion mediates the relationship between schedule control and WIF, and WIF mediates the relationship between schedule control and emotional exhaustion. Although time is one of the most important resources that an individual can possess (Nielsen, Bachrach, Sundstrom, \& Halfhill, 2012), there are also other forms of resources, such as feedback and social support (Bakker \& Demerouti, 2007; Schaufeli \& Bakker, 2004). Future research could address this point and examine other forms of job resources and its relationship with emotional exhaustion and work-family conflict. A similar suggestion is that future studies could examine other forms of resources at home such as family support (Adams, King, \& King, 1996) and its interactive effect with job resources on workplace or, more generally, life outcomes.

Second, since work-family conflict was theoretically grouped into three subdimensions, namely time-based, strain-based, and behavioural-based work-family conflicts (Greenhaus \& Beutell, 1985), future research could investigate the impact of both schedule control and family time adequacy on all three dimensions of work-family conflict to see if there would be a difference. For example, the impact of schedule control on time-based and strainbased work-family conflict may be stronger than that of behaviour-based work-family conflict because schedule control is closer to the time and strain sources of conflict. Finally, the sample used in the current study was from a large health care centre and the majority of participants were female. Future studies could use more genderbalanced samples in other industries to test the generalisability of the current research model. 


\section{Conclusion}

In summary, the current research drew upon the resources perspective (Grzywacz \& Marks, 2000; ten Brummelhuis \& Bakker, 2012) and the job demands-resources model (Bakker \& Demerouti, 2007) to investigate the reciprocal mediation relationship between schedule control, WIF, and emotional exhaustion. The findings first revealed that emotional exhaustion mediates the relationship between schedule control and WIF, while WIF also mediates the schedule control-emotional exhaustion relationship. In addition, the mediation path of schedule control to workfamily conflict via emotional exhaustion was stronger for employees with a high level of family time adequacy. With these findings on the resource-based process of the relationship between schedule control and work-family conflict, and suggested future directions, the current study contributes to a more comprehensive understanding of the mechanism of the impact of personal resources on individual and organisational outcomes.

\section{References}

Adams, G.A., King, L.A., \& King, D.W. (1996). Relationships of job and family involvement, family social support, and work-family conflict with job and life satisfaction. Journal of Applied Psychology, 81, 411-420.

Andrews, F.M., \& Withey, S.B. (1976). Social indicators of wellbeing. New York: Plenum.

Bacharach, S.B., Bamberger, P.A., \& Conley, S. (1991). Workhome conflict among nurses and engineers: Mediating the impact of role stress on burnout and satisfaction at work. Journal of Organizational Behavior, 12, 39-53.

Bakker, A.B., \& Demerouti, E. (2007). The job demandsresources model: State of the art. Journal of Managerial Psychology, 22, 309-328.

Bedeian, A.G., Burke, B.G., \& Moffett, R.G. (1988). Outcomes of work-family conflict among married male and female professionals. Journal of Management, 14, 475-491.

Beutell, N.J. (2010). Work schedule, work schedule control and satisfaction in relation to work-family conflict, work-family synergy, and domain satisfaction. Career Development International, 15, 501-518.

Bray, J.W., Kelly, E.L., Hammer, L.B., Almeida, D.M., Dearing, J.W., King, R.B., \& Buxton, O.M. (2013). An integrative, multilevel, and transdisciplinary research approach to challenges of work, family, and health. Methods report. Research Triangle Park, NC: RTI Press.

Burke, R.J. (1988). Some antecedents and consequences of workfamily conflict. Journal of Social Behavior \& Personality, 3, 287-302.

Diener, E., \& Ryan, K. (2008). Subjective well-being: A general overview. Southern African Journal of Psychology, 39, 391406.

Diestel, S., Rivkin, W., \& Schmidt, K.-H. (2015). Sleep quality and self-control capacity as protective resources in the daily emotional labor process: Results from two diary studies. Journal of Applied Psychology, 100, 809-827.
Edwards, J.R., \& Lambert, L.S. (2007). Methods for integrating moderation and mediation: A general analytical framework using moderated path analysis. Psychological Methods, 12, $1-22$.

Fenwick, R., \& Tausig, M. (2001). Scheduling stress family and health outcomes of shift work and schedule control. American Behavioral Scientist, 44, 1179-1198.

Frone, M.R. (2003). Work-family balance. In J.C. Quick \& L.E. Tetrick (Eds.), Handbook of occupational health psychology (pp. 143-162). Washington, DC: American Psychological Association.

Frone, M.R., Russell, M., \& Cooper, M.L. (1992). Antecedents and outcomes of work-family conflict: Testing a model of the work-family interface. The Journal of Applied Psychology, $77,65-78$.

Glass, J., \& Fujimoto, T. (1995). Employer characteristics and the provision of family-responsive policies. Work and Occupations, 22, 380-411.

Goff, S.J., Mount, M.K., \& Jamison, R.L. (2006). Employer supported child care, work/family conflict, and absenteeism: A field study. Personnel Psychology, 43, 793-809.

Greenhaus, J.H., \& Beutell, N.J. (1985). Sources of conflict between work and family roles. Academy of Management Review, 10, 76-88.

Griffin, M.A. (1997). Interaction between individuals and situations: Using HLM procedures to estimate reciprocal relationships. Journal of Management, 23, 759-773.

Grzywacz, J.G., \& Marks, N.F. (2000). Reconceptualizing the work-family interface: An ecological perspective on the correlates of positive and negative spillover between work and family. Journal of Occupational Health Psychology, 5, 111126.

Hayes, A.F. (2013). Introduction to mediation, moderation, and conditional process analysis: A regression-based approach. New York, NY: Guilford Press.

Hobfoll, S.E. (1989). Conservation of resources: A new attempt at conceptualizing stress. The American Psychologist, 44, 513524.

Hughes, E.L., \& Parkes, K.R. (2007). Work hours and well-being: The roles of work-time control and work-family interference. Work \& Stress, 21, 264-278.

Karasek, R. a. (1979). Job demands, job decisions latitude and mental strain: Implocations for job redesign. Administrative Science Quarterly, 24, 285-308.

Kelly, E.L., \& Moen, P. (2007). Rethinking the clockwork of work: Why schedule control may pay off at work and at home. Advances in Developing Human Resources, 9, 487-506.

Kenny, D.A. (1995). The effect of nonindependence on significance testing in dyadic research. Personal Relationships, 2, $67-75$.

Lapierre, L.M., \& Allen, T.D. (2012). Control at work, control at home, and planning behavior: Implications for work-family conflict. Journal of Management, 38, 1500-1516.

Lian, H., Ferrin, D.L., Morrison, R., \& Brown, D.J. (2014). Blame it on the supervisor or the subordinate? Reciprocal relations 
between abusive supervision and organizational deviance. Journal of Applied Psychology, 99, 651-64.

Maslach, C., \& Jackson, S. (1981). The measurement of experienced burnout. Journal of Occupational Behavior, 2, 99-113.

Maslach, C., \& Jackson, S.E. (1986). Maslach Burnout Inventory: Human Services Survey (research ed.). Palo Alto, CA: Consulting Psychologists Press.

Meier, L.L., \& Spector, P.E. (2013). Reciprocal effects of work stressors and counterproductive work behavior: a five-wave longitudinal study. Journal of Applied Psychology, 98, 529-39.

Michel, J.S., Kotrba, L.M., Mitchelson, J.K., Clark, M.A., \& Baltes, B.B. (2011). Antecedents of work-family conflict: A metaanalytic review. Journal of Organizational Behavior, 32, 689725.

Muthén, L.K., \& Muthén, B.O. (1998-2012). Mplus user's guide (7th ed.). Los Angeles, CA: Muthén \& Muthén.

Netemeyer, R.G., \& Boles, J.S. (1996). Development and validation of Work-Family Conflict and Family-Work Conflict Scales. Journal of Applied Psychology, 81, 400-410.

Nielsen, T.M., Bachrach, D.G., Sundstrom, E., \& Halfhill, T.R. (2012). Utility of OCB: Organizational citizenship behavior and group performance in a resource allocation framework. Journal of Management, 38, 668-694.

Nohe, C., \& Sonntag, K. (2014). Work-family conflict, social support, and turnover intentions: A longitudinal study. Journal of Vocational Behavior, 85, 1-12.
Pleck, J.H., Staines, G.L., \& Lang, L. (1980). Conflicts between work and family life. Monthly Labor Review, 103, 29-32.

Preacher, K.J., Rucker, D.D., \& Hayes, A.F. (2007). Addressing moderated mediation hypotheses: Theory, methods, and prescriptions. Multivariate Behavioral Research, 42, 185-227.

Schaufeli, W.B., \& Bakker, A.B. (2004). Job demands and job resources and their relationship with burnout and engagement: A multiple-sample study. Journal of Organizational Behavior, 25, 293-315.

Shrout, P.E., \& Fleiss, J.L. (1979). Intraclass correlations: Uses in assessing rater reliability. Psychological Bulletin, 86, 420-428.

ten Brummelhuis, L.L., \& Bakker, A.B. (2012). A resource perspective on the work-home interface: The work-home resources model. American Psychologist, 67, 545-556.

Thomas, L.T., \& Ganster, D.C. (1995). Impact of familysupportive work variables on work-family conflict and strain: A control perspective. Journal of Applied Psychology, $80,6-15$.

Van der Doef, M., \& Maes, S. (1999). The job demand-control (-support) model and psychological well-being: A review of 20 years of empirical research. Work \& Stress, 13, 87-114.

Van Horn, M.L., Bellis, J.M., \& Snyder, S.W. (2001). Family resource scale-revised: Psychometrics and validation of a measure of family resources in a sample of low-income families. Journal of Psychoeducational Assessment, 19, 54-68. 